\title{
Characterization and Properties of Activated Carbon Prepared from Tamarind Seeds by KOH Activation for Fe(III) Adsorption from Aqueous Solution
}

\author{
Sumrit Mopoung, ${ }^{1}$ Phansiri Moonsri, ${ }^{2}$ Wanwimon Palas, ${ }^{2}$ and Sataporn Khumpai ${ }^{2}$ \\ ${ }^{1}$ Department of Chemistry, Faculty of Science, Naresuan University, Phitsanulok, Thailand \\ ${ }^{2}$ Naresuan University Secondary Demonstration School, Naresuan University, Phitsanulok, Thailand \\ Correspondence should be addressed to Sumrit Mopoung; sumritm@nu.ac.th
}

Received 19 July 2015; Revised 20 October 2015; Accepted 9 November 2015

Academic Editor: Jaya N. Sahu

Copyright ( $) 2015$ Sumrit Mopoung et al. This is an open access article distributed under the Creative Commons Attribution License, which permits unrestricted use, distribution, and reproduction in any medium, provided the original work is properly cited.

\begin{abstract}
This research studies the characterization of activated carbon from tamarind seed with $\mathrm{KOH}$ activation. The effects of $0.5: 1-1.5: 1$ $\mathrm{KOH}$ : tamarind seed charcoal ratios and $500-700^{\circ} \mathrm{C}$ activation temperatures were studied. FTIR, SEM-EDS, XRD, and BET were used to characterize tamarind seed and the activated carbon prepared from them. Proximate analysis, percent yield, iodine number, methylene blue number, and preliminary test of $\mathrm{Fe}(\mathrm{III})$ adsorption were also studied. $\mathrm{Fe}(\mathrm{III})$ adsorption was carried out by $30 \mathrm{~mL}$ column with 5-20 ppm Fe(III) initial concentrations. The percent yield of activated carbon prepared from tamarind seed with $\mathrm{KOH}$ activation decreased with increasing activation temperature and impregnation ratios, which were in the range from 54.09 to $82.03 \mathrm{wt} \%$. The surface functional groups of activated carbon are $\mathrm{O}-\mathrm{H}, \mathrm{C}=\mathrm{O}, \mathrm{C}-\mathrm{O},-\mathrm{CO}_{3}, \mathrm{C}-\mathrm{H}$, and $\mathrm{Si}-\mathrm{H}$. The XRD result showed high crystallinity coming from a potassium compound in the activated carbon. The main elements found in the activated carbon by EDS are $\mathrm{C}, \mathrm{O}, \mathrm{Si}$, and $\mathrm{K}$. The results of iodine and methylene blue adsorption indicate that the pore size of the activated carbon is mostly in the range of mesopore and macropore. The average BET pore size and BET surface area of activated carbon are $67.9764 \AA$ and $2.7167 \mathrm{~m}^{2} / \mathrm{g}$, respectively. Finally, the tamarind seed based activated carbon produced with $500^{\circ} \mathrm{C}$ activation temperature and $1.0: 1 \mathrm{KOH}$ : tamarind seed charcoal ratio was used for Fe(III) adsorption test. It was shown that Fe(III) was adsorbed in alkaline conditions and adsorption increased with increasing $\mathrm{Fe}$ (III) initial concentration from 5 to 20 ppm with capacity adsorption of $0.0069-0.019 \mathrm{mg} / \mathrm{g}$.
\end{abstract}

\section{Introduction}

Tamarind (Tamarindus indica L.) was planted on a large scale in India, Thailand, Indonesia, Myanmar, and the Philippines. Tamarind fruit consists of pulp and hard-coated seeds. The seeds are $30-40 \%$ of fruit with a large quantity as agrobyproduct [1]. Tamarind seed powder has been used as a biosorbent for removal of $\mathrm{Cr}(\mathrm{VI})$ from simulated industrial wastewater [2]. Tamarind seed has also been used as a raw material for granular activated carbon prepared by microwave induced chemical activation for the adsorptive treatment of semiaerobic landfill leachate [3]. In addition, tamarind seed was activated by $\mathrm{H}_{2} \mathrm{SO}_{4}$ at $150^{\circ} \mathrm{C}$. The activated carbon product could adsorb $\mathrm{Cr}(\mathrm{VI})$ up to $29.7 \mathrm{mg} / \mathrm{g}$ at $\mathrm{pH}$ 1-3 [4]
Pollution of natural water resources by iron is one of the most important problems that face and threaten the world. Fe contaminants are produced from liquid wastes discharged from a number of industries [5]. Water with high iron content can be very objectionable in taste, odour, or appearance. With severe iron poisoning, much of the damage to the gastrointestinal tract and liver may be the result of highly localized iron concentration and free radical production leading to hepatotoxicity through lipid peroxidation and the destruction of the hepatic mitochondria. With this result, the liver becomes cirrhotic. Hepatoma, the primary cancer of the liver, has become the most common cause of death among patients with hemochromatosis [6]. Activated carbon has been proved to be an excellent adsorbent for removing 
organic or inorganic pollutants [7]. It could be produced from agricultural byproducts with low cost and abundance [8].

In this research, tamarind seed was used as precursor for the production of activated carbon using $\mathrm{KOH}$ activation. The effects of $\mathrm{KOH}$ :tamarind seed ratios and activation temperature were studied. The physical and chemical properties were characterized. The adsorption of iodine and methylene blue was also determined. Finally, the activated carbon prepared in this study was used in preliminary test for $\mathrm{Fe}(\mathrm{III})$ adsorption from aqueous solution.

\section{Materials and Methods}

2.1. Preparation of Material. Tamarind seed (sweet Thai tamarind) was obtained from Nakhon Thai district, Phitsanulok province, Thailand. It was washed and oven dried (SL 1375 SHEL LAB $1350 \mathrm{FX}$ ) at $105^{\circ} \mathrm{C}$ for $3 \mathrm{~h}$. Proximate analysis was used to determine the ash content [9], volatile matter [10], fixed carbon [11], and moisture content [12].

2.2. Preparation of Charcoal. Accurately weighed samples of dried tamarind seed (weighed with analytical balance, Sartorius Basic) were carbonized in a closed crucible (size 105/73 and $102 / 70$ ) at $500^{\circ} \mathrm{C}$ in furnace (Fisher Scientific Isotemp Muffle Furnace) for $1 \mathrm{~h}$. The charcoal product was ground and sieved to $2 \mathrm{~mm}$ size. The percent yield of tamarind seed based charcoal is $40.14 \%$.

2.3. Preparation of Activated Carbon. The tamarind seed charcoal was mixed with $\mathrm{KOH}$ (CARLO ERBA Reagent) using $\mathrm{KOH}$ to tamarind seed charcoal ratios of $0.5: 1,1.0: 1$, and $1.5: 1$ (wt/wt). The mixtures were activated at $500^{\circ} \mathrm{C}$, $600^{\circ} \mathrm{C}$, and $700^{\circ} \mathrm{C}$ in furnace. Fourier transform infrared spectrometer (Spectrum GX, PerkinElmer) in the range of $4000-400 \mathrm{~cm}^{-1}$ was used for characterization of functional groups on surface of the all samples. The samples were prepared as pellets using $\mathrm{KBr}$ (IR grade) [13]. An X-ray powder diffractometer with a $\mathrm{Cu}$ tube anode (PW 3040/60, X'Pert Pro MPD) was used to record the X-ray patterns of samples. Scanning electron microscopy (PHILIPS LEO $1455 \mathrm{VP}$ ) was used to visualize the surface morphology of the carbonized and activated products. The samples were coated with gold by a gold sputtering device for a clear vision of the surface morphology. Elemental composition of these samples was also determined using scanning electron microscopy equipped with energy dispersive spectrometer (EDS). The EDS spectra showing elemental composition were obtained by scanning through the surfaces of the samples. The surface distributions were collected from SEM pictures using different magnifications. Textural characteristics of only activated carbon prepared using the $1.0: 1 \mathrm{KOH}$ : charcoal ratio with $500^{\circ} \mathrm{C}$ activation were determined by $\mathrm{N}_{2}$ adsorption at $-196^{\circ} \mathrm{C}$ on Brunauer-Emmett-Teller surface area analyzer (Micromeritics TriStar II). The samples were degassed at $250^{\circ} \mathrm{C}$ for $12 \mathrm{~h}$ under vacuum before the measurements. The specific surface areas were estimated by the multipoint Brunauer-Emmett-Teller (BET) equation. The iodine $(0.1 \mathrm{~N}$, CARLO ERBA Reagent) and methylene blue (100 ppm, AR

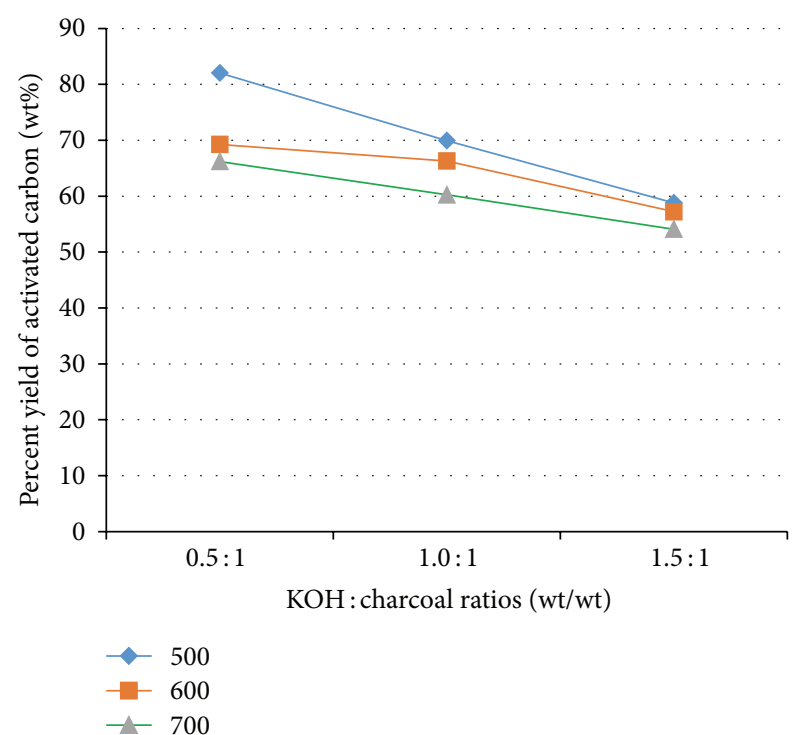

FIGURE 1: Percent yield of tamarind seed based activated carbon as a function of $\mathrm{KOH}$ : tamarind seed charcoal ratio and activation temperature.

UNILAB) numbers were also determined for all activated carbons.

2.4. Fe Adsorption. The activated carbon prepared using $1.0: 1 \mathrm{KOH}$ to charcoal mixture with activation at $500^{\circ} \mathrm{C}$ was used for Fe adsorption experiment. Accurately weighed samples of activated carbon were filled into $30 \mathrm{~mL}$ columns. Solutions of $\mathrm{FeCl}_{3}$ (AR UNILAB) at initial concentrations of 5,10 , and $20 \mathrm{ppm}(\mathrm{pH} 7.96 \pm 0.33$ ) were passed through the column. The eluted solutions were collected for Fe(III) concentration determination by AAS Varian SpectrAA 220 (Australia). Fe(III) adsorptions were calculated in $\mathrm{mg} \mathrm{Fe} / \mathrm{g}$ activated carbon. The $\mathrm{pH}$ of $\mathrm{Fe}$ (III) solution and leachate were measured by $\mathrm{pH}$ meter (HORIBA F-21, Japan). The $\mathrm{pH}$ of activated carbon (1:1 weight/volume of activated carbon to $\mathrm{H}_{2} \mathrm{O}$ ) was also measured by method of Bansode et al. [14].

\section{Results and Discussion}

3.1. Proximate Analysis of Tamarind Seed and Percent Yield of Activated Carbon. The proximate composition of tamarind seed is $1.14 \pm 0.07 \mathrm{wt} \%$ moisture, $1.65 \pm 0.04 \mathrm{wt} \%$ ash, $67.64 \pm$ $1.30 \mathrm{wt} \%$ volatile matter, and $28.89 \pm 0.45 \mathrm{wt} \%$ fixed carbon, which makes it suitable precursor for obtaining activated carbon [15].

The percent yield of tamarind seed based activated carbon decreases as activation temperature increases from 500 to $700^{\circ} \mathrm{C}$ (Figure 1). This could be attributed to the higher reaction rate of carbon and $\mathrm{KOH}$ to release more volatile components with concomitant improvement in the textural characteristics [16] and carbon burn-off [17].

3.2. Adsorption of Iodine. Determining the iodine number is one of the methods to determine the adsorption capacity 


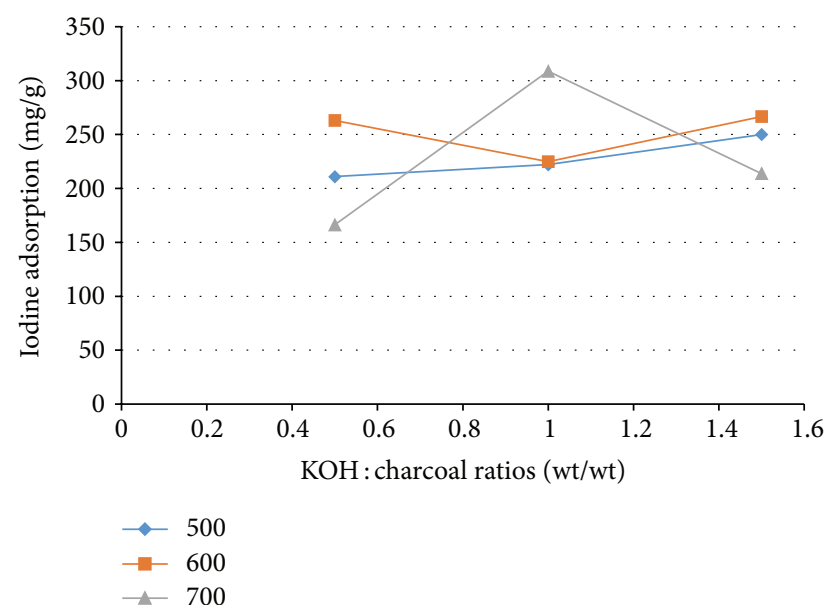

FIGURE 2: Iodine adsorption of tamarind seed based activated carbon as a function of $\mathrm{KOH}$ : tamarind seed charcoal ratio and activation temperature.

of activated carbons. It is a measure of the micropore (0$20 \AA$ ) content of the activated carbon by adsorption of iodine from solution. The typical range is $500-1200 \mathrm{mg} / \mathrm{g}$, which is equivalent to surface area of carbon between 900 and $1100 \mathrm{~m}^{2} / \mathrm{g}$ [17].

It can be seen from Figure 2 that iodine adsorption of activated carbon prepared with activation at $500^{\circ} \mathrm{C}$ slightly increases with increasing impregnation ratios. It was shown that micropore content on surface of activated carbon is slightly increased with increasing impregnation ratios. This is attributed to more extensive reaction between $\mathrm{KOH}$ and surface carbon [18], leading to increased release of $\mathrm{CO}_{2}$ and $\mathrm{CO}$ gases and creating micropores inside of the mesopores [19]. The iodine adsorption of activated carbon prepared with activation temperature of $600^{\circ} \mathrm{C}$ and $1.0: 1$ impregnation ratio is lower than that of activated carbon prepared with impregnation ratios of $0.5: 1$ and $1.5: 1$. This may be attributed to more extensive reaction of $\mathrm{KOH}$ and surface carbon at 0.5:1 impregnation ratio [18] and more excessive carbon burn-off at 1.5:1 impregnation ratio [17]. However, the iodine adsorption of activated carbon prepared with activation temperature of $600^{\circ} \mathrm{C}$ is higher than that of activated carbon prepared with activation temperature of $500^{\circ} \mathrm{C}$ for all impregnation ratios. This is due to more extensive volatile matter degradation and increased reaction of $\mathrm{KOH}$ and surface carbon at higher activation temperature [20]. The iodine adsorption at the activation temperature of $700^{\circ} \mathrm{C}$ was highest for activated carbon prepared using 1.0:1 impregnation ratio. The iodine adsorption of activated carbon prepared with $1.5: 1$ impregnation ratio was higher than that of activated carbon prepared with $0.5: 1$ impregnation ratio. It was shown that more micropores are created at impregnation ratios $<1.0: 1$, but the content of micropores decreases at impregnation ratios $\geq 1.0: 1$ due to more excess carbon burn-off, collapse of pore walls [18], or expansion of micropores to mesopores [19]. Furthermore, the reaction between carbon and $\mathrm{KOH}$ may damage the micropores on the carbon surface because the concentration of $\mathrm{KOH}$ solution is too high [21].

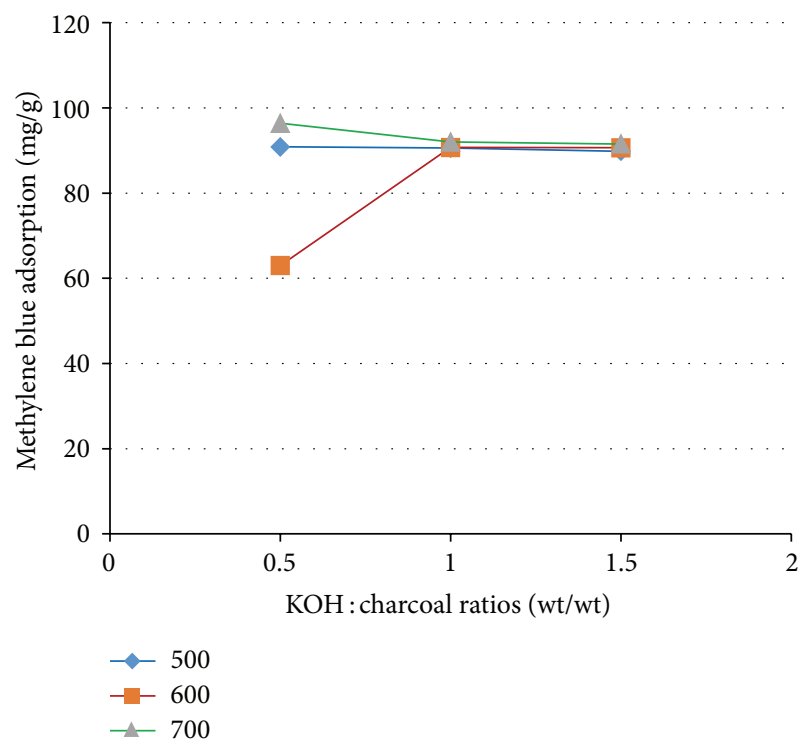

FIGURE 3: Methylene blue adsorption of tamarind seed based activated carbon as a function of $\mathrm{KOH}$ : tamarind seed charcoal ratio and activation temperature.

3.3. Adsorption of Methylene Blue. Activated carbon is amphoteric material, which can be positively or negatively charged depending on the solution $\mathrm{pH}$. Attraction between activated carbon and anionic or cationic guest materials is mainly related to the surface characteristics. More negatively charged surfaces are obtained at higher $\mathrm{pH}$ values and this favors the uptake of more cationic groups due to decreased electrostatic repulsion between cations and the surface of activated carbon and vice versa [22]. Methylene blue $\left(\mathrm{C}_{16} \mathrm{H}_{18} \mathrm{~N}_{3} \mathrm{SCl}\right)$ is a cationic dye with the estimated dimensions of $1.43 \mathrm{~nm} \times 0.61 \mathrm{~nm} \times 0.4 \mathrm{~nm}$ and its adsorption by activated carbon is very susceptible to solution $\mathrm{pH}$. The adsorption of methylene blue involves the electrostatic interaction of methylene blue cations with negatively charged carbon surface functional groups [22].

Figure 3 shows the methylene blue adsorption on tamarind seed based activated carbon. It was shown that the methylene blue adsorption capacity of tamarind seed based activated carbon is very high. This revealed the fact that the pore size of activated carbon is mainly in the mesopore regime and has negative surface charge, which corresponds to resorcinol-formaldehyde based activated carbon [19] and corncob based activated carbon [23], with $\mathrm{KOH}$ activation. Tamarind seed has pores with size mainly in the mesopore range [3]. As a result, tamarind seed based activated carbon is mainly mesoporous and has high methylene blue adsorption capacity. Another effect is the surface charge of activated carbon, which is negative at high $\mathrm{pH}$ [22]. The methylene blue adsorption on tamarind seed based activated carbon activated at $500^{\circ} \mathrm{C}$ is relatively constant for all impregnation ratios of $\mathrm{KOH}$ : tamarind seed. This could be explained by relatively small change in the mesopore portion of initial tamarind seed during activation at $500^{\circ} \mathrm{C}$. For activated carbon prepared at $600^{\circ} \mathrm{C}$, the methylene blue adsorption 


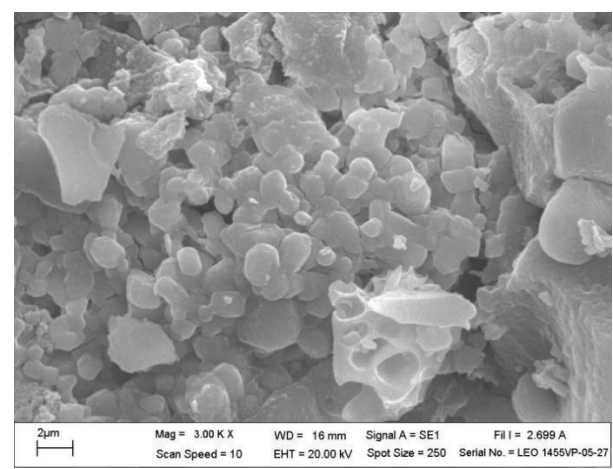

(a)

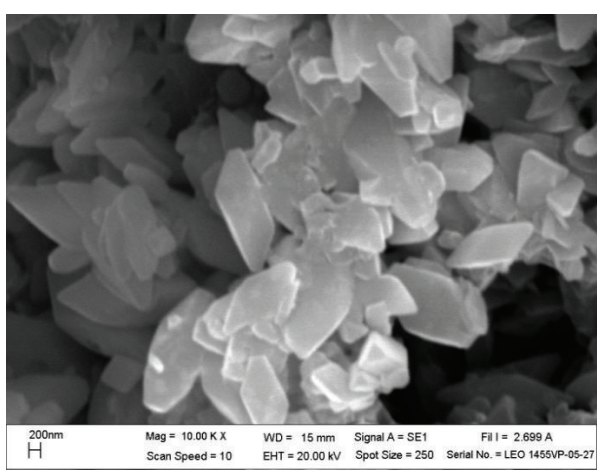

(b)

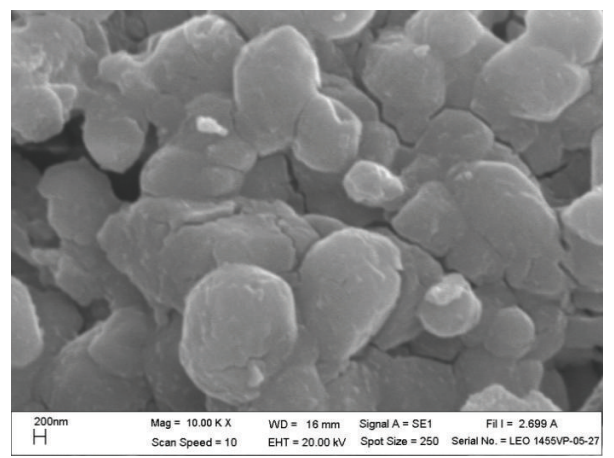

(c)

FIGURE 4: Scanning electron micrographs (a-c) and elemental composition determined by EDS (Table 1) of tamarind seed based activated carbon prepared with $1.0: 1$ impregnation ratio and activated at $500^{\circ} \mathrm{C}$.

increases with impregnation ratio rising from $0.5: 1$ to $1.0: 1$ and then remains constant. At impregnation ratio of $0.5: 1$ used for the preparation of activated carbon at $600^{\circ} \mathrm{C}$, the methylene blue adsorption is lower than that of activated carbons prepared at $500^{\circ} \mathrm{C}$ and $700^{\circ} \mathrm{C}$. It may be attributed to new micropores being created inside of the mesopores. This is the result of a higher coverage activated carbon surface with potassium compounds, which will inhibit the physical surface [23]. Another reason might be the decomposition of negatively charged surface groups with more material being released by $\mathrm{KOH}$ activation at high temperature, especially $\mathrm{OH}$ group of $\mathrm{KOH}$ [16]. At increasing impregnation ratios more volatile matter is released and more carbon burn-off takes place [17] leading to more mesopores or macropores. For carbon activated at $700^{\circ} \mathrm{C}$, there is a slight downward trend from ratio $0.5: 1$ to $1.0: 1$ and then methylene blue adsorption remains constant. However, the methylene blue adsorption is nearly equal for reagent ratios $1.0: 1$ and $1.5: 1$ at all of the activation temperatures. This can be explained by the mesopore remaining unchanged with increasing burnoff [24]. Additionally, the charcoal starting materials were soaked in a large amount of $\mathrm{KOH}$ and a thin film of $\mathrm{KOH}$ should be coated on their surface and the interior of charcoals should be covered with $\mathrm{KOH}$ completely. During the activation in an inert atmosphere surface pyrolysis does not occur on the surface of chars, causing the surface structure to remain [25]. Finally, the strongly basic concentrated $\mathrm{KOH}$ solution might also destroy the pore structure of carbon [21].
TABLE 1

\begin{tabular}{lcc}
\hline Element & Wt\% & At\% \\
\hline $\mathrm{C}$ & 22.96 & 37.03 \\
$\mathrm{O}$ & 34.15 & 41.35 \\
$\mathrm{Si}$ & 01.95 & 01.35 \\
$\mathrm{~K}$ & 40.94 & 20.28 \\
\hline
\end{tabular}

These results are in accordance with the results of BET, where the average BET pore size of activated carbon is $67.9764 \AA$.

3.4. SEM-EDS. SEM images of tamarind seed based activated carbon with $1.0: 1$ impregnation ratio at an activation temperature of $500^{\circ} \mathrm{C}$ are shown in Figure 4 . It can be seen from the micrographs that the external surface of the activated carbon particles has cracks, crevices (Figures 4(a) and 4(c)), and some crystals of various sizes in large holes. The crystals in the macropores (Figure 4(b)) are most likely the potassium compounds as is hinted at by the results of the EDS. The EDS showed (Table 1) high content of potassium in the activated carbon. This is due to activation in the presence of $\mathrm{KOH}$, where $\mathrm{K}_{2} \mathrm{CO}_{3}$ and other related compounds form during the pyrolysis process [18]. This result is also in good accordance with the results of BET because there is large amount of potassium compounds covering the surface of the activated carbon, leading to relatively low BET surface area of only $2.7167 \mathrm{~m}^{2} / \mathrm{g}$. 


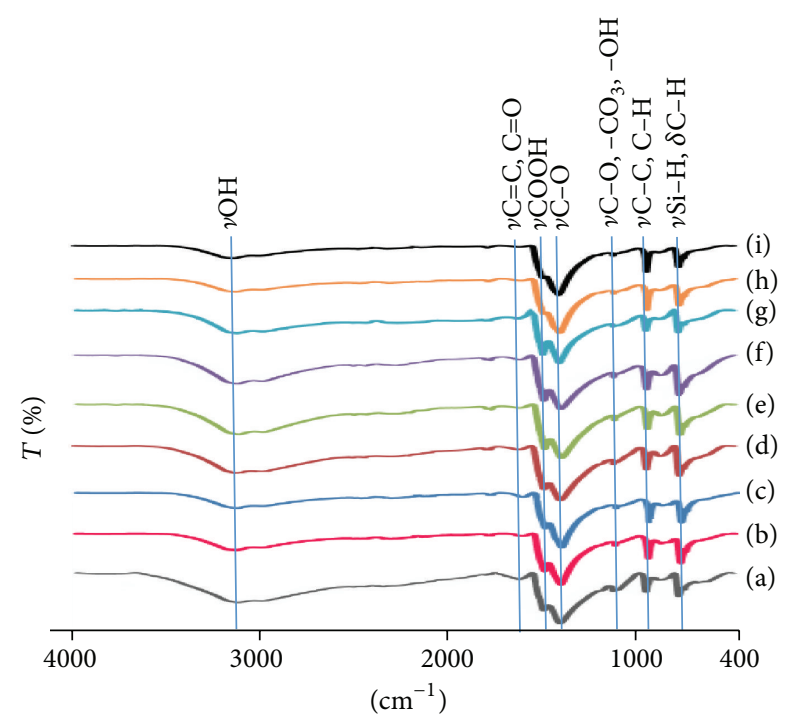

FIGURE 5: FTIR transmission spectra of (a) activated carbon prepared with $0.5: 1$ impregnation ratio and activated at $500^{\circ} \mathrm{C}$, (b) activated carbon prepared with $1.0: 1$ impregnation ratio and activated at $500^{\circ} \mathrm{C},(\mathrm{c})$ activated carbon prepared with $1.5: 1$ impregnation ratio and activated at $500^{\circ} \mathrm{C}$, (d) activated carbon prepared with $0.5: 1$ impregnation ratio and activated at $600^{\circ} \mathrm{C}$, (e) activated carbon prepared with $1.0: 1$ impregnation ratio and activated at $600^{\circ} \mathrm{C}$, (f) activated carbon prepared with $1.5: 1$ impregnation ratio and activated at $600^{\circ} \mathrm{C},(\mathrm{g})$ activated carbon prepared with $0.5: 1$ impregnation ratio and activated at $700^{\circ} \mathrm{C}$, (h) activated carbon prepared with $1.0: 1$ impregnation ratio and activated at $700^{\circ} \mathrm{C}$, and (i) activated carbon prepared with 1.5:1 impregnation ratio and activated at $700^{\circ} \mathrm{C}$.

Elemental analysis of the residue found the presence of $\mathrm{C}, \mathrm{O}, \mathrm{Si}$, and $\mathrm{K}$ (Table 1). Furthermore, it was found that carbon content was only $22.96 \mathrm{wt} \%$. This result is attributed to the reaction between $\mathrm{KOH}$ and $\mathrm{C}$, which is considered the main reaction [23]. It is expected that large amount of carbon decomposed by reaction with potassium hydroxide [16]. Therefore, the activated carbons obtained by $\mathrm{KOH}$ activation have higher potassium and oxygen contents. The content of $\mathrm{Si}$ in the activated carbon roughly corresponds to its content in the original tamarind seed.

3.5. FTIR Spectra. Figure 5 shows the FTIR spectra of tamarind seed based activated carbon prepared with $\mathrm{KOH}$ to tamarind seed charcoal ratios of $0.5-1.5$ and activated at 500$700^{\circ} \mathrm{C}$. It can be seen that all of spectra are similar. There are a broad band at about $3200 \mathrm{~cm}^{-1}$, very weak peak at $1600 \mathrm{~cm}^{-1}$, strong peak at $1400 \mathrm{~cm}^{-1}$, shoulder peak at $1500 \mathrm{~cm}^{-1}$, very weak peak at $1150 \mathrm{~cm}^{-1}$, and weak peaks at $900 \mathrm{~cm}^{-1}$ and $700 \mathrm{~cm}^{-1}$. The broad band at $3200 \mathrm{~cm}^{-1}$ associated with $-\mathrm{OH}$ stretching vibration of hydroxyl functional groups. The very weak peak at $1600 \mathrm{~cm}^{-1}$ corresponds to $\mathrm{C}=\mathrm{C}$ stretching of the aromatic rings [16]. These could form by decomposition of $\mathrm{C}-\mathrm{H}$ bonds to form a more stable aromatic $\mathrm{C}=\mathrm{C}$ bonds at the higher activation temperatures [26]. This feature may also be due to $\mathrm{C}=\mathrm{O}$ groups conjugated with aromatic rings [27]. This indicates the formation of carbonyl-containing groups formed during the aromatization of tamarind seed [28]. The intensity of this peak gradually decreases with increasing activation temperatures and impregnation ratios. The shoulder peaks at about $1500 \mathrm{~cm}^{-1}$ and $1400 \mathrm{~cm}^{-1}$ are attributed to carboxyl-carbonate structures [21]. The peak at $1400 \mathrm{~cm}^{-1}$ can be attributed to oxygen containing functional groups, for example, $\mathrm{C}=\mathrm{O}$ and $\mathrm{C}-\mathrm{O}$ of carboxylic groups [27] or in-plane vibration of $\mathrm{O}-\mathrm{H}$ of carboxylic group [29]. The very weak peak at about $1150 \mathrm{~cm}^{-1}$ corresponds to the stretching vibration of $\mathrm{C}-\mathrm{O}$ group in alcohol, phenol, ether, or ester [17]. It could also be attributed to carboxylic groups [29], including $-\mathrm{CO}_{3}$ group [18] and the phenolic $-\mathrm{OH}$ group [21]. The peak at $960 \mathrm{~cm}^{-1}$ is associated with stretching vibration of $\mathrm{C}-\mathrm{C}$ or $\mathrm{C}-\mathrm{H}$ groups [30] or $\mathrm{C}=\mathrm{O}$ group [31]. The peak at about $700 \mathrm{~cm}^{-1}$ may be due to $\mathrm{Si}-\mathrm{H}$ stretching vibration [30] or polycyclic and $\mathrm{C}-\mathrm{H}$ bending vibration of benzene rings [28]. These functional groups can have negative or positive charge depending on the solution $\mathrm{pH}$ [22].

As compared to tamarind seed char which had been prepared by Munusamy et al. [32], it showed the peaks of O$\mathrm{H}$ group $\left(3334 \mathrm{~cm}^{-1}\right), \mathrm{C}-\mathrm{H}$ group $\left(2879 \mathrm{~cm}^{-1}\right), \mathrm{C}=\mathrm{C}$ group $\left(1548 \mathrm{~cm}^{-1}\right)$, and $\mathrm{C}-\mathrm{C}$ group $\left(1165 \mathrm{~cm}^{-1}\right)$. It was shown that $\mathrm{NaOH}$ activation resulted in increased functional groups, except $\mathrm{CH}$ group which disappeared after activation.

3.6. XRD Diffractograms. The result of XRD diffractograms (Figure 6) revealed that the activated carbons may contain potassium compounds with high crystallinity after activation with $\mathrm{KOH}$. When compared to tamarind seed char [32], it showed only amorphous carbon (two broad peaks at around $2 \theta=24^{\circ}$ and $42^{\circ}$ ). This finding is similar to the petroleum coke based activated carbon prepared with $\mathrm{K}_{2} \mathrm{CO}_{3}$ activation [33] and Enteromorpha prolifera based activated carbon prepared with $\mathrm{KOH}$ activation [29]. The reaction of $\mathrm{KOH}$ and surface carbon $\left(\mathrm{C}_{\mathrm{f}}\right)$ occurring during activation process is as follows [27]:

$$
\begin{aligned}
4 \mathrm{KOH}+\mathrm{C}_{\mathrm{f}} & \longrightarrow \mathrm{K}_{2} \mathrm{CO}_{3}+\mathrm{K}_{2} \mathrm{O}+2 \mathrm{H}_{2} \\
\mathrm{~K}_{2} \mathrm{CO}_{3}+2 \mathrm{C}_{\mathrm{f}} & \longrightarrow 2 \mathrm{~K}+3 \mathrm{CO} \\
\mathrm{K}_{2} \mathrm{O}+\mathrm{C} & \longrightarrow \mathrm{C}-\mathrm{O}-\mathrm{K}+\mathrm{K} \\
\mathrm{C}-\mathrm{O}-\mathrm{K}+\mathrm{H}_{2} \mathrm{O} & \longrightarrow \mathrm{C}-\mathrm{O}-\mathrm{H}+\mathrm{KOH}
\end{aligned}
$$

The reaction on surface of carbon could be explained by the following equation [23]:

$$
\begin{aligned}
& 2 \mathrm{KOH} \longrightarrow \mathrm{K}_{2} \mathrm{O}+\mathrm{H}_{2} \mathrm{O} \text { (dehydration) } \\
& \mathrm{C}_{\mathrm{f}}+\mathrm{H}_{2} \mathrm{O} \longrightarrow \mathrm{H}_{2}+\mathrm{CO} \text { (water-gas reaction) } \\
& \mathrm{CO}+\mathrm{H}_{2} \mathrm{O} \longrightarrow \mathrm{H}_{2} \\
&+\mathrm{CO}_{2} \text { (water-gas shift reaction) } \\
& \mathrm{K}_{2} \mathrm{O}+\mathrm{CO}_{2} \longrightarrow \mathrm{K}_{2} \mathrm{CO}_{3} \text { (carbonate formation) }
\end{aligned}
$$

The final product of activation in the presence of $\mathrm{KOH}$ during the preparation of activated carbon is $\mathrm{K}_{2} \mathrm{CO}_{3}$ (8). $\mathrm{K}$ metal was 

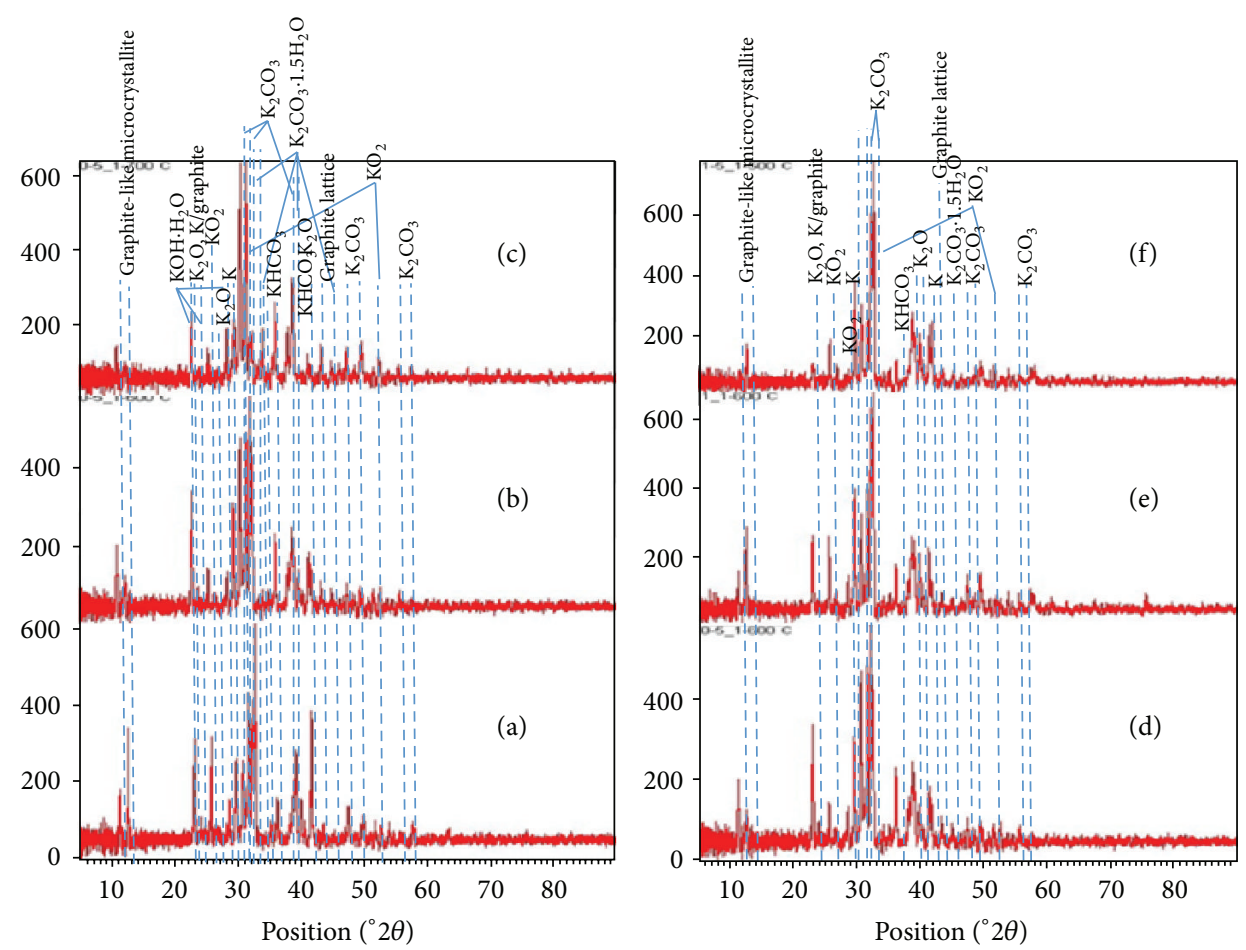

FIGURE 6: XRD diffractograms of (a) activated carbon prepared with $0.5: 1$ impregnation ratio and activated at $500^{\circ} \mathrm{C}$, (b) activated carbon prepared with $0.5: 1$ impregnation ratio and $600^{\circ} \mathrm{C}$ activation temperature, (c) activated carbon with $0.5: 1$ impregnated ratio and $700^{\circ} \mathrm{C}$ activation temperature, (d) activated carbon with $0.5: 1$ impregnated ratio and $600^{\circ} \mathrm{C}$ activation temperature, (e) activated carbon with $1.0: 1$ impregnated ratio and $600^{\circ} \mathrm{C}$ activation temperature, and (f) activated carbon with $1.5: 1$ impregnated ratio and $600^{\circ} \mathrm{C}$ activation temperature.

produced during the activation process at $>700^{\circ} \mathrm{C}$ as shown in following equation [23]:

$$
\begin{aligned}
& \mathrm{K}_{2} \mathrm{O}+\mathrm{H}_{2} \longrightarrow 2 \mathrm{~K}+\mathrm{H}_{2} \mathrm{O} \text { (reduction by hydrogen) } \\
& \mathrm{K}_{2} \mathrm{O}+\mathrm{C}_{\mathrm{f}} \longrightarrow 2 \mathrm{~K}+\mathrm{CO} \text { (reduction by carbon) }
\end{aligned}
$$

Reactions (9) and (10) occurred at temperatures above $780^{\circ} \mathrm{C}$, which is the boiling point of potassium, leading to high loss of potassium [23]. During $\mathrm{KOH}$ activation process a gasification reaction occurred in which $\mathrm{KOH}$ was reduced to $\mathrm{K}$ metal. $\mathrm{K}_{2} \mathrm{CO}_{3}$, which also formed during the activation, was reduced by carbon to $\mathrm{K}, \mathrm{K}_{2} \mathrm{O}, \mathrm{CO}$, and $\mathrm{CO}_{2}$ and porous carbon surface was also created at the same time. Since the boiling point of $\mathrm{K}$ is $780^{\circ} \mathrm{C}$, then potassium metal remains in the activated carbon [18].

Figure $6(\mathrm{a}-\mathrm{c})$ shows the effect of activation temperature $\left(500-700^{\circ} \mathrm{C}\right)$ with impregnation ratio of $0.5: 1$ on crystallinity of the activated carbon. The effect of impregnation ratios $(0.5: 1-1.5: 1)$ on the crystallinity of activated carbon prepared at activation temperature of $600^{\circ} \mathrm{C}$ is shown in Figure $6(\mathrm{~d}-$ f). These show presence of peaks of many potassium compounds. For example, the peaks at $23^{\circ}, 27^{\circ}$, and $39.5^{\circ}$ correspond to $\mathrm{K}_{2} \mathrm{O}$, which forms at temperatures above $500^{\circ} \mathrm{C}$. The intensity of these peaks increases with increasing activation temperature (Figure 6(a-c)), but their intensity decreases with increasing impregnation ratio for materials prepared at $600^{\circ} \mathrm{C}$ (Figure $5(\mathrm{~d}-\mathrm{f})$ ). The peaks at $22.5^{\circ}, 23.5^{\circ}, 28^{\circ}$, and $31.5^{\circ}$ belong to peaks corresponding to $\mathrm{KOH} \cdot \mathrm{H}_{2} \mathrm{O}$. These peaks are very weak at activation temperatures above $500^{\circ} \mathrm{C}$. This shows that $\mathrm{C}$ reduced almost all $\mathrm{KOH}$ into $\mathrm{K}_{2} \mathrm{CO}_{3}$ and $\mathrm{K}$. The peaks corresponding to $\mathrm{K}$ metal appear at $29^{\circ}$ and $42^{\circ}$. These peaks appear for materials prepared at $500^{\circ} \mathrm{C}$ and above. Furthermore, the intensity of these peaks tends to increase as the activation temperature and impregnation ratios increase. The peaks of $\mathrm{K}_{2} \mathrm{CO}_{3}$ and $\mathrm{K}_{2} \mathrm{CO}_{3} \cdot 1.5 \mathrm{H}_{2} \mathrm{O}$ occur at $30.5^{\circ}, 31.5^{\circ}$, and $38.5^{\circ}$ and $32^{\circ}, 33^{\circ}, 39.5^{\circ}$, and $46.5^{\circ}$, respectively. The small peaks at $46^{\circ}, 49^{\circ}, 56^{\circ}$, and $58^{\circ}$ can also be attributed to $\mathrm{K}_{2} \mathrm{CO}_{3}$ [34]. The intensity of these peaks increased with increasing impregnation ratios, which is associated with increased reduction of $\mathrm{KOH}$. However, the intensity of the peaks of $\mathrm{K}_{2} \mathrm{CO}_{3} \cdot 1 \cdot 5 \mathrm{H}_{2} \mathrm{O}$ decreased as activation temperature increased. This indicates that the extent of dehydration was higher with increasing activation temperature. As a result of this, the peaks corresponding to $\mathrm{K}_{2} \mathrm{CO}_{3}$ increase in intensity as the activation temperature increases. The peaks of $\mathrm{KO}_{2}$ and ordered $\mathrm{K} /$ graphite occurred at $26^{\circ}$ and $31^{\circ}$ and at $53^{\circ}$ and $23^{\circ}$, respectively. The presence of these species is the result of partial oxidation of potassium graphite intercalate via chemical reduction of $\mathrm{C}-\mathrm{O}-\mathrm{C}$ or $\mathrm{C}-\mathrm{O}-\mathrm{H}$ surface functional groups [35]. The content of $\mathrm{KO}_{2}$ decreases as activation temperature increases but increases as impregnation ratios increase. Furthermore, the peaks of ordered K/graphite decrease with increasing activation temperature and decreasing impregnation ratios. This suggests that, after activation, activated carbon had an amorphous structure and the graphite crystallites are 


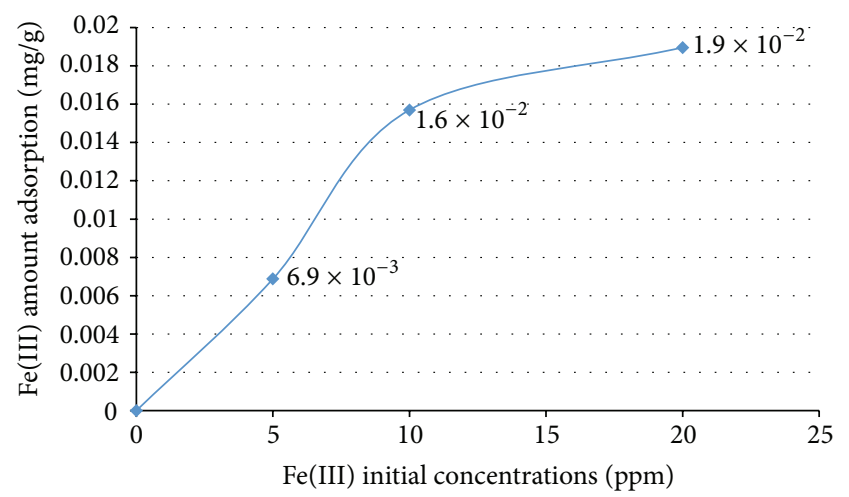

FIgURE 7: $\mathrm{Fe}(\mathrm{III})$ adsorption on tamarind seed based activated carbon as a function of initial Fe(III) concentration.

destroyed by $\mathrm{K}$ intercalation [27]. The peaks at $35^{\circ}, 37^{\circ}$, and $28^{\circ}$ associated with $\mathrm{KHCO}_{3}$, which formed from interaction of $\mathrm{K}_{2} \mathrm{CO}_{3}, \mathrm{H}_{2} \mathrm{O}$, and $\mathrm{CO}_{2}$ in air during cooling stage [36]. Its content increased with increasing activation temperatures and impregnation. These results are in agreement with the results of FTIR and EDS, which showed presence of $-\mathrm{OH}$ and $-\mathrm{CO}_{3}$ groups and $\mathrm{K}$, respectively. The low intensity peaks at around $23.5^{\circ}$ and $44^{\circ}$ correspond to the graphite lattice, which demonstrate that the degree of ordered graphitization of activated carbon decreases at higher activation temperatures and impregnation ratios [37]. Finally, the peaks between $10^{\circ}$ and $20^{\circ}$ are attributed to the presence of micropores and microcrystallinity in the activated carbon [26], which may be due to graphite-like microcrystalline structure of multilayer stacks [38].

3.7. $\mathrm{Fe}$ (III) Adsorption. Fe(III) adsorption capacity of tamarind seed based activated carbon increased (0.0069$0.019 \mathrm{mg} / \mathrm{g}$ ) with initial 5-10 ppm Fe(III) concentration (Figure 7). This result can be attributed to the higher initial concentration providing a higher driving force to overcome mass transfer resistance. It may also be due to higher interaction between $\mathrm{Fe}$ (III) and activated carbon. As the activated carbon offers a finite number of surface binding sites, $\mathrm{Fe}(\mathrm{III})$ adsorption showed a saturation trend at higher initial $\mathrm{Fe}(\mathrm{III})$ concentration [30]. In this experiment, the $\mathrm{pH}$ of $\mathrm{Fe}$ (III) solution is $7.96 \pm 0.33$, which is higher than the $\mathrm{pH}_{\mathrm{ZPC}}$ (zero point of charge) of tamarind seed based activated carbon (6.00) as reported by Agarwal et al. [2] under similar conditions. At $\mathrm{pH}>6$, the net surface charge of tamarind seed based activated carbon is negative [2]. Therefore, Fe(III) cations can be adsorbed on the negatively charged surface of activated carbon at solution $\mathrm{pH}$ above 6 [39].

\section{Conclusion}

Tamarind seed could be used for charcoal and activated carbon preparation. The yield of charcoal product from tamarind seed prepared by carbonization at $500^{\circ} \mathrm{C}$ is $40.14 \mathrm{wt} \%$. The percent yield of activated carbon prepared from tamarind seed with $\mathrm{KOH}$ activation ranges from 54.09 to $82.03 \mathrm{wt} \%$ using impregnation ratios of $0.5: 1-1.5: 1$ and activation temperatures of $500-700^{\circ} \mathrm{C}$. The surface functional groups present on tamarind seed based activated carbon after activation with $\mathrm{KOH}$ are $\mathrm{O}-\mathrm{H}, \mathrm{C}=\mathrm{O}, \mathrm{C}-\mathrm{O},-\mathrm{CO}_{3}, \mathrm{C}-\mathrm{H}$, and $\mathrm{Si}-\mathrm{H}$. These functional groups can be negatively or positively charged depending on the solution $\mathrm{pH}$. The XRD results indicate the presence of a range of potassium compounds on the surface of activated carbon, such as $\mathrm{K}, \mathrm{K}_{2} \mathrm{CO}_{3}$, $\mathrm{K}_{2} \mathrm{CO}_{3} \cdot 1.5 \mathrm{H}_{2} \mathrm{O}, \mathrm{KHCO}_{3}, \mathrm{KO}_{2}$, and $\mathrm{K}_{2} \mathrm{O}$. The main elements present in the activated carbon are $\mathrm{C}, \mathrm{O}, \mathrm{Si}$, and $\mathrm{K}$. The results of iodine and methylene adsorption, SEM, and BET confirmed that the pores of the activated carbon are mostly in range of mesopores to macropores. The average BET pore size of activated carbon is $67.9764 \AA$. Fe(III) adsorptions capacity of tamarind seed based activated carbon activated at $500^{\circ} \mathrm{C}$ using $\mathrm{KOH}$ to tamarind seed charcoal ratio of $1.0: 1$ is 6.9 $\times 10^{-3}-1.9 \times 10^{-2} \mathrm{mg} / \mathrm{g}$, as determined in experiments with initial $\mathrm{Fe}(\mathrm{III})$ concentrations of 5-20 ppm at $\mathrm{pH} 7.96 \pm 0.33$. The next step, Fe absorption should be further study for find the maximum condition, isotherm and kinetic.

\section{Conflict of Interests}

The authors declare that there is no conflict of interests regarding the publication of this paper.

\section{Acknowledgments}

This research was supported by Science Classrooms in University-Affiliated School Project, Ministry of Science and Technology of Thailand, and Faculty of Science, Naresuan University, and was partially supported by the Department of Chemistry and Naresuan University Secondary Demonstration School, Naresuan University.

\section{References}

[1] T. Ramesh, N. Rajalakshmi, and K. S. Dhathathreyan, "Activated carbons derived from tamarind seeds for hydrogen storage," Journal of Energy Storage, vol. 4, pp. 89-95, 2015.

[2] G. S. Agarwal, H. K. Bhuptawat, and S. Chaudhari, "Biosorption of aqueous chromium(VI) by Tamarindus indica seeds," Bioresource Technology, vol. 97, no. 7, pp. 949-956, 2006.

[3] K. Y. Foo, L. K. Lee, and B. H. Hameed, "Preparation of tamarind fruit seed activated carbon by microwave heating for the adsorptive treatment of landfill leachate: a laboratory column evaluation," Bioresource Technology, vol. 133, pp. 599605, 2013.

[4] S. Gupta and B. V. Babu, "Utilization of waste product (tamarind seeds) for the removal of $\mathrm{Cr}(\mathrm{VI})$ from aqueous solutions: equilibrium, kinetics, and regeneration studies," Journal of Environmental Management, vol. 90, no. 10, pp. 3013-3022, 2009.

[5] E. M. Soliman, S. A. Ahmed, and A. A. Fadl, "Reactivity of sugar cane bagasse as a natural solid phase extractor for selective removal of $\mathrm{Fe}(\mathrm{III})$ and heavy-metal ions from natural water samples," Arabian Journal of Chemistry, vol. 4, no. 1, pp. 63-70, 2011.

[6] G. N. Kousalya, M. R. Gandhi, C. S. Sundaram, and S. Meenakshi, "Synthesis of nano-hydroxyapatite chitin/chitosan 
hybrid biocomposites for the removal of Fe(III)," Carbohydrate Polymers, vol. 82, no. 3, pp. 594-599, 2010.

[7] J. Kong, Q. Yue, L. Huang et al., "Preparation, characterization and evaluation of adsorptive properties of leather waste based activated carbon via physical and chemical activation," Chemical Engineering Journal, vol. 221, pp. 62-71, 2013.

[8] E. Köseoğlu and C. Akmil-Başar, "Preparation, structural evaluation and adsorptive properties of activated carbon from agricultural waste biomass," Advanced Powder Technology, vol. 26, no. 3, pp. 811-818, 2015.

[9] American Standards for Testing of Materials, "Standard test method for total ash content of activate carbon," ASTM D 286694, American Standards for Testing of Materials, 1996.

[10] American Standards for Testing of Materials, "Standard test method for volatile matter content of activate carbon," ASTM D 5832-95, American Standards for Testing of Materials, 1996.

[11] American Standard of Testing Material, "Standard test method for fixed carbon in activate carbon," ASTM D 3172-89, American Standard of Testing Material, 1994.

[12] American Standard of Testing Material. Standard Test Method for Moisture in Activate Carbon ASTM D 2867-95, 1996.

[13] R. Yang, G. Liu, X. Xu, M. Li, J. Zhang, and X. Hao, "Surface texture, chemistry and adsorption properties of acid blue 9 of hemp (Cannabis sativa L.) bast-based activated carbon fibers prepared by phosphoric acid activation," Biomass and Bioenergy, vol. 35, no. 1, pp. 437-445, 2011.

[14] R. R. Bansode, J. N. Losso, W. E. Marshall, R. M. Rao, and R. J. Portier, "Pecan shell-based granular activated carbon for treatment of chemical oxygen demand (COD) in municipal wastewater," Bioresource Technology, vol. 94, no. 2, pp. 129-135, 2004.

[15] R. R. Gil, B. Ruiz, M. S. Lozano, and E. Fuente, "Influence of the pyrolysis step and the tanning process on $\mathrm{KOH}$-activated carbons from biocollagenic wastes. Prospects as adsorbent for $\mathrm{CO}_{2}$ capture," Journal of Analytical and Applied Pyrolysis, vol. 110, no. 1, pp. 194-204, 2014.

[16] Y. Chen, B. Huang, M. Huang, and B. Cai, "On the preparation and characterization of activated carbon from mangosteen shell," Journal of the Taiwan Institute of Chemical Engineers, vol. 42, no. 5, pp. 837-842, 2011.

[17] C. Saka, "BET, TG-DTG, FT-IR, SEM, iodine number analysis and preparation of activated carbon from acorn shell by chemical activation with $\mathrm{ZnCl}_{2}$," Journal of Analytical and Applied Pyrolysis, vol. 95, pp. 21-24, 2012.

[18] H. Deng, G. Li, H. Yang, J. Tang, and J. Tang, "Preparation of activated carbons from cotton stalk by microwave assisted $\mathrm{KOH}$ and $\mathrm{K}_{2} \mathrm{CO}_{3}$ activation," Chemical Engineering Journal, vol. 163, no. 3, pp. 373-381, 2010.

[19] T. Mitome, Y. Uchida, Y. Egashira, K. Hayashi, A. Nishiura, and N. Nishiyama, "Adsorption of indole on $\mathrm{KOH}$-activated mesoporous carbon," Colloids and Surfaces A: Physicochemical and Engineering Aspects, vol. 424, pp. 89-95, 2013.

[20] M. Loredo-Cancino, E. Soto-Regalado, F. J. Cerino-Córdova, R. B. García-Reyes, A. M. García-León, and M. T. Garza-González, "Determining optimal conditions to produce activated carbon from barley husks using single or dual optimization," Journal of Environmental Management, vol. 125, pp. 117-125, 2013.

[21] L. Yang, X.-W. Chou, C. Li, X.-L. Long, and W.-K. Yuan, "Reduction of [Fe(III)EDTA] $]^{-}$catalyzed by activated carbon modified with $\mathrm{KOH}$ solution," Journal of Industrial and Engineering Chemistry, vol. 19, no. 3, pp. 784-790, 2013.
[22] Y. Gokce and Z. Aktas, "Nitric acid modification of activated carbon produced from waste tea and adsorption of methylene blue and phenol," Applied Surface Science, vol. 313, pp. 352-359, 2014.

[23] R.-L. Tseng, S.-K. Tseng, F.-C. Wu, C.-C. Hu, and C.-C. Wang, "Effects of micropore development on the physicochemical properties of $\mathrm{KOH}$-activated carbons," Journal of the Chinese Institute of Chemical Engineers, vol. 39, no. 1, pp. 37-47, 2008.

[24] F.-C. Wu, R.-L. Tseng, and C.-C. Hu, "Comparisons of pore properties and adsorption performance of $\mathrm{KOH}$-activated and steam-activated carbons," Microporous and Mesoporous Materials, vol. 80, no. 1-3, pp. 95-106, 2005.

[25] R.-L. Tseng and S.-K. Tseng, "Pore structure and adsorption performance of the $\mathrm{KOH}$-activated carbons prepared from corncob," Journal of Colloid and Interface Science, vol. 287, no. 2, pp. 428-437, 2005.

[26] L. Muniandy, F. Adam, A. R. Mohamed, and E.-P. Ng, "The synthesis and characterization of high purity mixed microporous/mesoporous activated carbon from rice husk using chemical activation with $\mathrm{NaOH}$ and $\mathrm{KOH}$," Microporous and Mesoporous Materials, vol. 197, pp. 316-323, 2014.

[27] Y. Ji, T. Li, L. Zhu, X. Wang, and Q. Lin, "Preparation of activated carbons by microwave heating $\mathrm{KOH}$ activation," Applied Surface Science, vol. 254, no. 2, pp. 506-512, 2007.

[28] A. A. Ceyhan, Ö. Şahin, O. Baytar, and C. Saka, "Surface and porous characterization of activated carbon prepared from pyrolysis of biomass by two-stage procedure at low activation temperature and it's the adsorption of iodine," Journal of Analytical and Applied Pyrolysis, vol. 104, pp. 378-383, 2013.

[29] Y. Gao, Q. Yue, B. Gao et al., "Comparisons of porous, surface chemistry and adsorption properties of carbon derived from Enteromorpha prolifera activated by $\mathrm{H}_{4} \mathrm{P}_{2} \mathrm{O}_{7}$ and $\mathrm{KOH}$," Chemical Engineering Journal, vol. 232, pp. 582-590, 2013.

[30] H. Cherifi, B. Fatiha, and H. Salah, "Kinetic studies on the adsorption of methylene blue onto vegetal fiber activated carbons," Applied Surface Science, vol. 282, pp. 52-59, 2013.

[31] M. A. Kader, M. R. Islam, M. Parveen, H. Haniu, and K. Takai, "Pyrolysis decomposition of tamarind seed for alternative fuel," Bioresource Technology, vol. 149, pp. 1-7, 2013.

[32] K. Munusamy, R. S. Somani, and H. C. Bajaj, "Tamarind seeds carbon: preparation and methane uptake," BioResources, vol. 6, no. 1, pp. 537-551, 2011.

[33] C. $\mathrm{Lu}, \mathrm{S}$. $\mathrm{Xu}$, and C. Liu, "The role of $\mathrm{K}_{2} \mathrm{CO}_{3}$ during the chemical activation of petroleum coke with $\mathrm{KOH}$," Journal of Analytical and Applied Pyrolysis, vol. 87, no. 2, pp. 282-287, 2010.

[34] X.-F. Li, Y. Zuo, Y. Zhang, Y. Fu, and Q.-X. Guo, "In situ preparation of $\mathrm{K}_{2} \mathrm{CO}_{3}$ supported Kraft lignin activated carbon as solid base catalyst for biodiesel production," Fuel, vol. 113, pp. 435-442, 2013.

[35] J. A. Michel and C. M. Lukehart, "Partially oxidized potassium intercalate of ultradispersed diamond: a cautionary note," Carbon, vol. 86, pp. 12-14, 2015.

[36] Y.-D. Chen, M.-J. Huang, B. Huang, and X.-R. Chen, "Mesoporous activated carbon from inherently potassium-rich pokeweed by in situ self-activation and its use for phenol removal," Journal of Analytical and Applied Pyrolysis, vol. 98, pp. 159-165, 2012.

[37] K. Wang, N. Zhao, S. Lei et al., "Promising biomass-based activated carbons derived from willow catkins for high performance supercapacitors," Electrochimica Acta, vol. 166, pp. 1-11, 2015. 
[38] Y. Huang, E. Ma, and G. Zhao, “Thermal and structure analysis on reaction mechanisms during the preparation of activated carbon fibers by $\mathrm{KOH}$ activation from liquefied wood-based fibers," Industrial Crops and Products, vol. 69, pp. 447-455, 2015.

[39] A. Üçer, A. Uyanik, S. Çay, and Y. Özkan, "Immobilisation of tannic acid onto activated carbon to improve Fe(III) adsorption," Separation and Purification Technology, vol. 44, no. 1, pp. 11-17, 2005. 

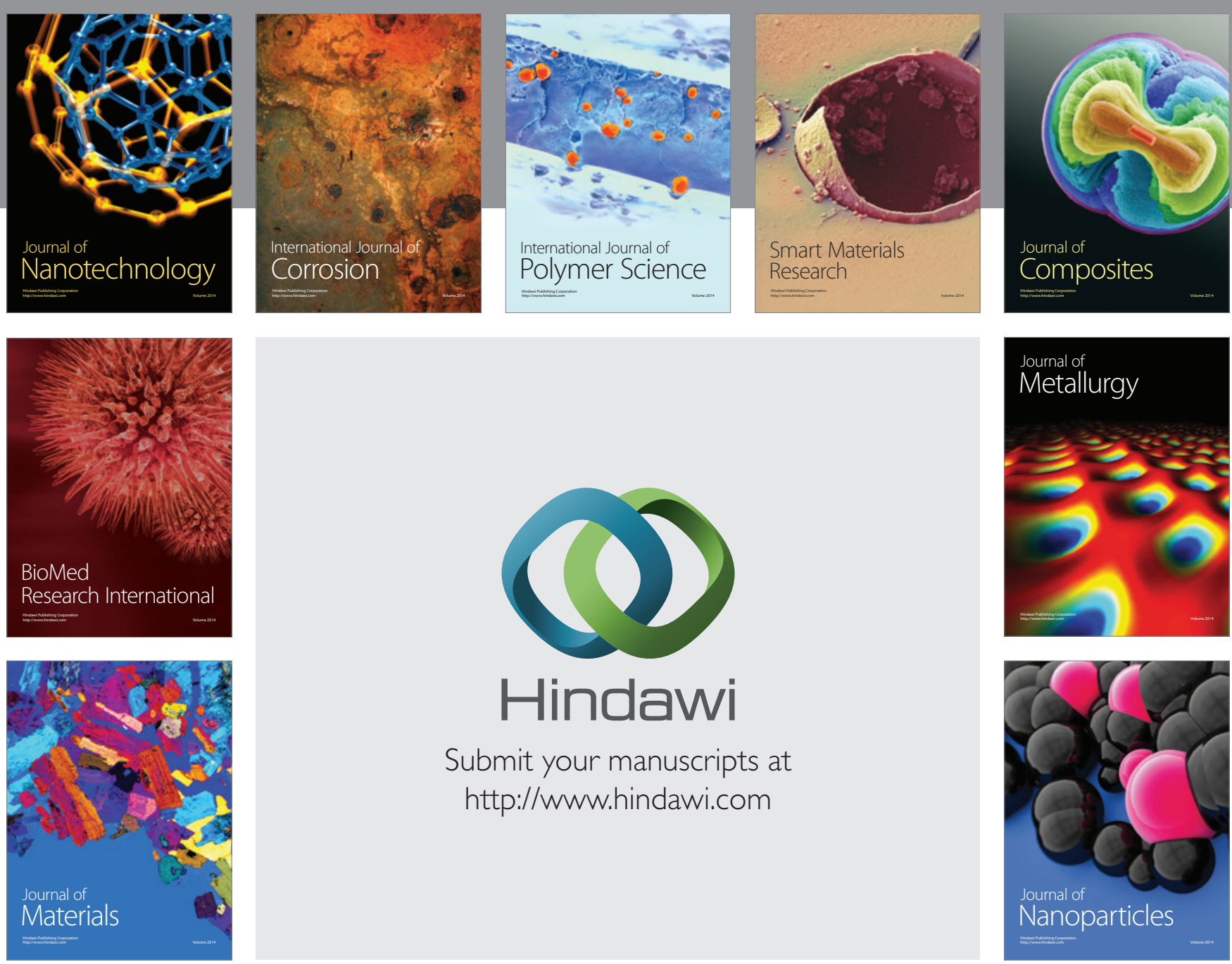

Submit your manuscripts at http://www.hindawi.com
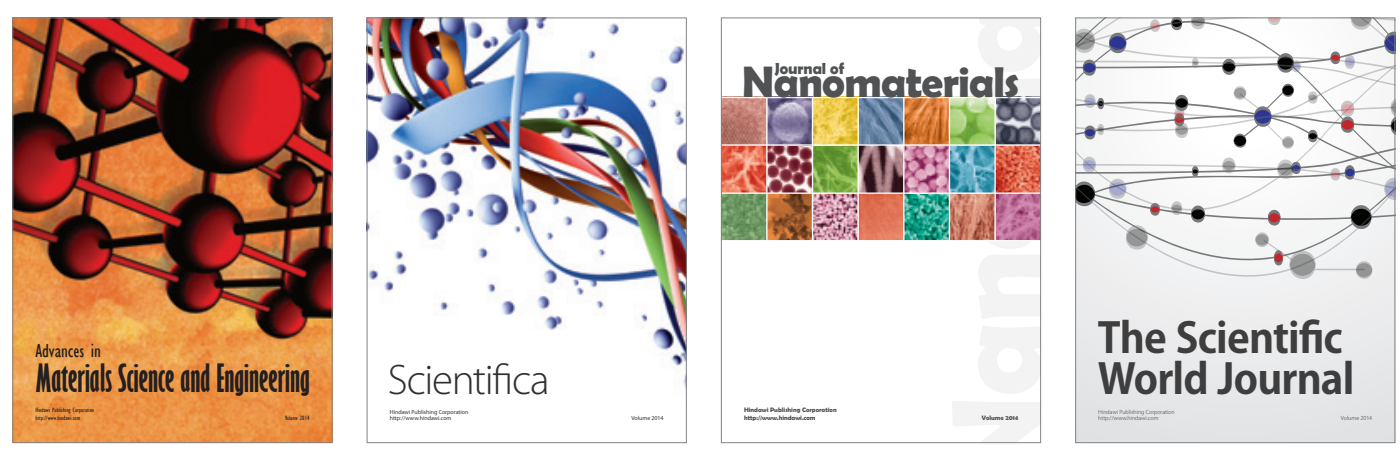

\section{The Scientific World Journal}
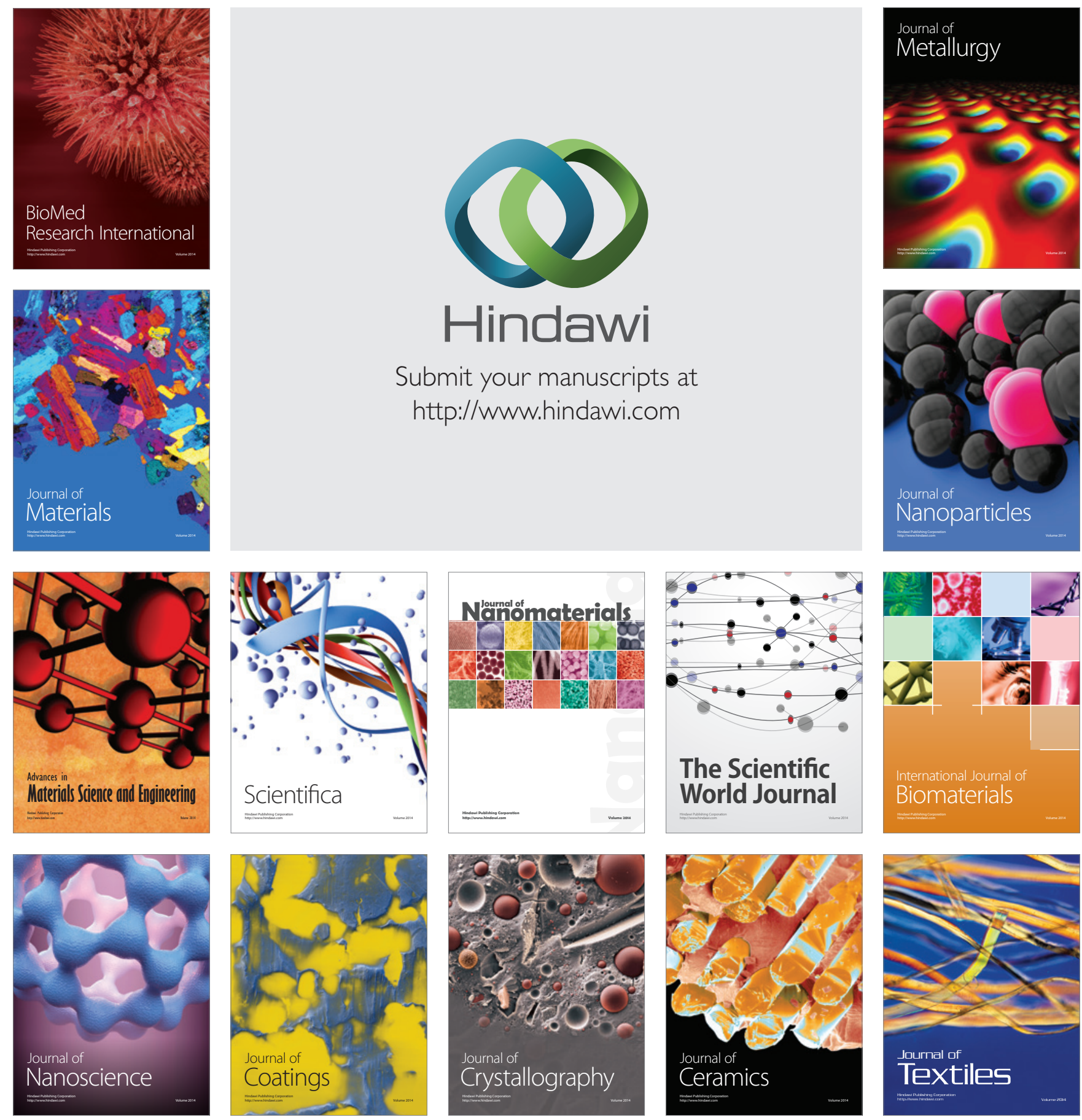